\title{
Sexual Dysfunction and Fertility Problems in Men with Inflammatory Bowel Disease
}

\author{
Yong Eun Park (iD), Tae Oh Kim(iD) \\ Division of Gastroenterology, Department of Internal Medicine, Haeundae Paik Hospital, Inje University College of Medicine, Busan, Korea
}

\begin{abstract}
Inflammatory bowel disease (IBD) is a chronic inflammatory disorder of the gastrointestinal tract that is usually diagnosed in young individuals. Crohn's disease and ulcerative colitis are the 2 principal forms of IBD. Patients with IBD demonstrate varying degrees of disease activity and sometimes need to undergo bowel surgery such as proctocolectomy with ileal pouch-anal anastomosis that involves removal of the entire colon and rectum with consequent sexual dysfunction. Several studies have shown that sulfasalazine, affects male fertility. Additionally, many men with IBD are unable to control their smoking, drinking, and eating habits, which can cause worsening of disease activity and fertility. Therefore, infertility and sexual dysfunction are important issues in young patients diagnosed with IBD because they are related to optimal management of the disease and patients' quality of life. Only a few studies have reported sexual dysfunction and infertility in men with IBD. Therefore, this study reviewed the current literature describing male sexual dysfunction scales and evaluated the causes of sexual dysfunction and infertility in men with IBD.
\end{abstract}

Keywords: Crohn's disease; Erectile dysfunction; Inflammatory bowel diseases; Male infertility; Sexual dysfunction, physiological; Ulcerative colitis

This is an Open Access article distributed under the terms of the Creative Commons Attribution Non-Commercial License (http://creativecommons.org/licenses/by-nc/4.0) which permits unrestricted non-commercial use, distribution, and reproduction in any medium, provided the original work is properly cited.

\section{INTRODUCTION}

Inflammatory bowel disease (IBD) is a chronic inflammatory disorder of the gastrointestinal tract that is usually diagnosed in young individuals between 15 and 40 years of age [1,2]. Crohn's disease (CD) and ulcerative colitis (UC) are the 2 principal forms of IBD. IBD is more common in Western countries than in other parts of the world; however, its prevalence is rapidly increasing in Asia, particularly in Korea [3,4]. Although IBD can occur at any age, based on current studies, the median ages at diagnosis of UC and CD in Koreans are 35 years and 21.5 years, respectively [3]. Patients with IBD show an early onset of symptoms and undergo various medical treatments in their $20 \mathrm{~s}, 30 \mathrm{~s}$, or 40s. Therefore, improving sexual dysfunction (SD) and quality of life in these patients is important. Additionally, the rate of SD in patients with IBD is $45 \%$ to $60 \%$ in women and $15 \%$ to $25 \%$ in men [5,6], which is higher than the SD rates of $30 \%$ and $5 \%$ in women and men, respectively, observed in the general population $[7,8]$. Therefore, SD is a serious concern among many patients with IBD and significantly affects patients' quality of life. Only a few studies have described SD

Received: Jan 12, 2019 Revised: Jan 29, 2019 Accepted: Feb 10, 2019 Published online Mar 22, 2019

Correspondence to: Tae Oh Kim (iD https://orcid.org/0000-0002-7359-1599

Division of Gastroenterology, Department of Internal Medicine, Haeundae Paik Hospital, Inje University College of Medicine, 875 Haeundae-ro, Haeundae-gu, Busan 48108, Korea.

Tel: +82-51-797-0220, Fax: +82-51-797-0011, E-mail: kto0440@paik.ac.kr 
in men with IBD. SD is associated with infertility and other pregnancy-related complications [9]. Patients with IBD demonstrating disease aggravation and requiring surgery and medical therapy, may develop infertility and lifestyle habits that could cause sexual difficulties $[9,10]$. This study reviewed SD in men with UC and CD.

\section{INFLAMMATORY BOWEL DISEASE AND SEXUAL DYSFUNCTION}

\section{Assessment of sexual dysfunction in}

\section{patients with inflammatory bowel disease}

Several studies have reported the use of different questionnaires and/or indices to assess quality of life (including sexual function) in patients with IBD. The Inflammatory Bowel Disease Quality of Life Questionnaire [11] includes only 1 question regarding sexual function, which is, "To what extent has your bowel problem limited sexual activity during the last 2 weeks?" [11]. Notably, no definite IBD-specific validated questionnaires are available to evaluate SD in patients with IBD. Several studies have been performed using general validated questionnaires and the International Index of Erectile Function (IIEF) [12].

\section{1) The International Index of Erectile Dysfunction}

IIEF is the most commonly used scale to assess male SD. The IIEF comprises 15 questions categorized into 5 domains of sexual function as follows: i) erectile function (Q 1, 2, 3, 4, 5, 15 [6 items]), ii) orgasmic function ( $\mathrm{Q}$ 9, 10 [2 items]), iii) sexual desire (Q 11, 12 [2 items]), iv) satisfaction with intercourse (Q 6, 7, 8 [3 items]), and v) overall satisfaction (Q 13, 14 [2 items]). Each question is assigned 0 to 5 points. Most questions (6/15) are associated with erectile function and are primarily applicable to the general elderly patient population [12]. Therefore, the IIEF is limited in assessing SD in most young patients with IBD. However, this tool is the most common questionnaire evaluating sexual function; thus, it has been applied to patients with IBD.

\section{2) Patient-Reported Outcomes Measurement Information System Sexual Function and Satisfaction measures}

The Patient-Reported Outcomes Measurement Information System Sexual Function and Satisfaction measure (PROMIS SexFS) (version 2.0) was developed and validated for the general population, including patients with chronic diseases [13,14]. The SexFS items are not disease-specific, but include items that evaluate satisfaction with the disease and symptoms. This tool measures sexual function and satisfaction within 30 days prior to the administration of the survey and is applicable to both sexes. For men, 4 domains are included as follows: erectile function, interest in sexual activity, orgasmic ability, and satisfaction with sex life [13]. Higher the SexFS score, higher the interest in sexual activity and satisfaction with sex life.

\section{3) European Organization for Research and Treatment of Cancer Study Group on Quality of Life}

The European Organization for Research and Treatment of Cancer Study Group on Quality of Life (EORTC-QLQ) is a tool that assesses the quality of life in patients with colorectal cancer. It includes questions regarding sexual function and satisfaction, as well as colorectal issues such as fecal continence and stoma function [15]. Timmer et al [16] reported that feeling attractive $(p=0.002)$ or feeling masculine $(p=0.005)$ were significantly influenced by disease activity in patients with IBD (based on the EORTC questionnaire) $(p<0.05)$.

\section{4) Inflammatory bowel disease-male sexual dysfunction scale}

O'Toole et al [17] reported a new IBD-specific psychometric tool to assess sexual function in men with IBD. They used a cross-sectional survey utilizing the IEF to evaluate male sexual function, as well as the Patient Health Questionnaire to evaluate depressive symptoms and patients' medical history and sociodemographic information to identify clinical factors associated with SD [17]. They identified 10 items that were included in the IBD-specific-male SD scale. No endoscopic data support this study, and this being a recently published study, it is difficult to confirm its reliability. However, it may serve as a new tool to measure sexual function and psychometric factors in men with IBD. The various questionnaires and/or tools to assess male sexual function have been summarized in Table 1.

\section{Definitions}

\section{1) Sexual dysfunction}

SD is an important cause of male infertility and is categorized as erectile dysfunction (ED), decreased li- 
Table 1. Comparison between questionnaires evaluating male sexual function

\begin{tabular}{lcc}
\hline \multicolumn{1}{c}{ Questionnaire } & $\begin{array}{c}\text { IBD- } \\
\text { specific }\end{array}$ & $\begin{array}{c}\text { Sexual function- } \\
\text { specific }\end{array}$ \\
\hline IIEF & No & Yes \\
IBD-Q & Yes & No \\
The PROMIS Sexual Function & No & Yes \\
and Satisfaction & & \\
EORTC-QLQ-CR 38 & No & No \\
IBD-MSDS & Yes & Yes \\
\hline
\end{tabular}

IBD: inflammatory bowel disease, IIEF: International Index of Erectile Function, IBD-Q: inflammatory bowel disease quality of life questionnaire, PROMIS: Patient-Reported Outcomes Measurement Information System, EORTC-QLQ-CR 38: The 38-item European Organization for Research and Treatment of Cancer Study Group on Quality of Life questionnaire, IBD-MSDS: Inflammatory Bowel Disease-Male Sexual Dysfunction Scale.

bido, and abnormal ejaculation [2]. Additionally, physiological and psychological factors such as body image perception, fertility concerns, and sexual desire also affect sexual function $[2,18]$.

\section{2) Infertility}

Infertility is defined as the inability to conceive within 12 months of unprotected sexual intercourse [19]. Primary infertility is defined as inability to conceive after 12 months despite regular unprotected sexual intercourse. Secondary infertility is defined as the inability to conceive after the birth of one or more biological children [20].

\section{Causes of sexual dysfunction}

\section{1) Surgery}

Surgery is recommended in patients with IBD who are refractory to conventional medical therapy or in patients who develop complications such as intestinal obstruction and toxic megacolon, which is defined as colonic diameter $>6 \mathrm{~cm}$ leading to colonic perforation and/or massive hemorrhage [21,22]. Patients with CD commonly develop complications including perianal abscesses, fistulas, and stenosis, necessitating surgery [23]. The ostomy rate in patients with severe perianal CD is $31 \%$ to $49 \%$ [24,25]. Patients with CD undergo various operations including seton placement, stricturoplasty, fistulotomy, and colectomy with ostomy [23]. The risk of malignancy associated with the detection of highgrade dysplasia and dysplasia-associated lesions or masses also commonly necessitates elective operations in patients with UC [21]. Previously, total proctocolectomy with end-ileostomy was the standard operation performed in patients with UC [26]; however, currently the most frequently performed procedure is restorative proctocolectomy with ileal pouch-anal anastomosis (IPAA) [27]. IPAA preserves the anal transition zone; therefore, normal defecation is maintained. However, the most common complication of IPAA is pouchitis (a non-specific inflammation of the ileal pouch) [21,27]. Proctocolectomy can injure the parasympathetic and sympathetic nerves intraoperatively, and/or cause fibrosis, anatomical alterations, and psychological disturbances [28]. Previous studies have investigated the role of the aforementioned surgeries in causing SD in men with IBD. Farouk et al [29] reported a study involving 762 men with UC who underwent IPAA and observed that $3 \%$ of these men developed retrograde or no ejaculation 10 years after IPAA. Berndtsson et al [30] reported that $12 \%$ of men with UC developed SD (ejaculatory dysfunction) after IPAA. A meta-analysis of 43 observational studies that reported post-IPAA complications showed that 21 studies examined SD and $3.6 \%$ of the 5,112 patients investigated reported SD [31]. A few studies have shown that age is an important risk factor for SD. Lindsey et al. showed a 3.8\% impotence rate in patients undergoing rectal dissection surgery, and all patients were aged $>50$ years [32]. Another study investigating the long-term outcomes after IPAA in young patients (median age at operation=18 years, and median follow-up=12.5 years) reported that no man showed impotence or retrograde ejaculation [33].

Several studies $[32,34]$ have shown that IPAA improves overall sexual functional outcomes and satisfaction despite SD. Gorgun et al [34] showed that the mean erectile function score increased to 2.12 points postoperatively $(\mathrm{p}=0.02)$; however, no significant difference was observed in complete and partial ED pre- and postoperatively $(p=0.29)$. Furthermore, a randomized, double-blind placebo-controlled trial investigating sildenafil (Viagra, a selective type-5 phosphodiesterase inhibitor), for ED in patients with IBD reported that $79 \%$ of men who underwent proctectomy showed improved erectile function [35].

In addition to IPAA, the other surgical options for IBD include end-ileostomy, ileo-rectal anastomosis, ileoanal anastomosis without a pouch, and the Koch pouch [10]; however, data regarding postoperative SD associated with these options are limited. A survey-based 
cross-sectional analysis performed in 280 men reported that creation of a stoma is associated with $\mathrm{ED}$ and diminished sexual satisfaction [16]. Kuruvilla et al [36] also reported that patients with UC who underwent ileostomy showed lower sexuality and body image scores than patients who underwent total proctocolectomy with IPAA. Therefore, although previous studies support the association between surgery and SD (Table 2), and although it is proven that sildenafil effectively manages postoperative SD, further research is needed to investigate in detail the effects of various types of surgeries on sexual function.

\section{2) Medical therapy}

\section{(1) 5-aminosalicylic acid}

Aminosalicylates are compounds containing 5-aminosalicylic acid (5-ASA) that show anti-inflammatory and immunomodulatory effects in the intestine. Sulfasalazine and mesalamine (which does not contain sulfa groups) are the commonly used agents in this category [37,38]. Sulfasalazine comprises 5-ASA and sulfapyridine. Sulfapyridine metabolites can adversely affect sperm and cause oligospermia, poor sperm motility, and increased risk of morphologically abnormal sperm $[39,40]$. However, several studies have reported reversal of adverse effects and restoration of function after discontinuation of 5-ASA [39,41-43]. In another study, 555 patients with UC were administered longterm sulfasalazine and 5-ASA. Of these 555 patients, 42 men showed abnormal semen parameters as follows: impaired motility (90.5\%), increased abnormal sperm morphology (47.6\%), and reduced sperm concentration (38\%). However, when 5-ASA was switched to another medication, all male fertility parameters improved after 3 months [44]. Riley et al [45] reported that among 9 of the 16 men with UC who switched to mesalamine (a 5-ASA compound without the sulfapyridine component), all 9 showed improved semen parameters. Several reports have described improvements in seminal fluid parameters in men who were switched to mesalamine $[44,45]$. However, a case report has described the development of oligospermia after mesalamine use in a young man [46]. Notably, discontinuation of the medication improved semen parameters to near-normal, and the patient's wife became pregnant thereafter [46]. Based on disease activity and a couple's desire to get pregnant, it is advisable to discontinue sulfasalazine or switch this medication to a different 5-ASA agent (without the sulfapyridine compound), if complete cessation of 5-ASA is contraindicated.

\section{(2) Corticosteroids}

Corticosteroids are potent anti-inflammatory drugs that are commonly used in patients with acute or moderate-to-severe disease activity in patients with

Table 2. Studies summarizing operations and sexual dysfunction in patients with IBD

\begin{tabular}{|c|c|}
\hline Type of operation & Studies evaluating sexual dysfunction \& infertility \\
\hline IPAA & $\begin{array}{l}\text { - } 3 \% \text { of men with UC [29] } \\
\text { - Retrograde or no ejaculation } 10 \text { years after IPAA } \\
\text { - } 12 \% \text { of men with UC [30] } \\
\text { - Ejaculatory dysfunction } \\
\text { - Meta-analysis of } 21 \text { studies [31] } \\
\text { - } 3.6 \% \text { of } 5,112 \text { patients evaluated } \\
\text { - Sexual dysfunction such as retrograde ejaculation, erection disorder, and dyspareunia } \\
\text { - Patients with IBD aged } \geq 50 \text { years [32] } \\
\text { - } 3.8 \% \text { impotence rate } \\
\text { - Young patients (median age } 18 \text { years) who underwent IPAA surgery [33] } \\
\text { - No impotence or retrograde ejaculation } \\
\text { - } 122 \text { men who underwent IPAA surgery [34] } \\
\text { - } 2.12 \text { point increase in the erectile function score (better sexual results) } \\
\text { - No significant difference between pre- and postoperative erectile dysfunction }(p=0.29)\end{array}$ \\
\hline Total proctocolectomy with end-ileostomy & $\begin{array}{l}\text { - Patients with UC [36] } \\
\text { - Lower sexuality and body image scores }\end{array}$ \\
\hline Stoma & $\begin{array}{l}\cdot 280 \text { men with IBD [16] } \\
\text { - Erectile dysfunction and decreased sexual satisfaction }\end{array}$ \\
\hline
\end{tabular}

UC: ulcerative colitis, IPAA: ileal pouch-anal anastomosis, IBD: inflammatory bowel disease. 
IBD [47,48]. Corticosteroids inhibit several inflammatory pathways, such as the interleukin (IL) and the nuclear factor kappa-light-chain-enhancer of activated B cell complex pathways and also trigger apoptosis of gut lymphocytes [47]. There is a lack of research on the relationship between steroids and infertility. Lerman et al [49] investigated the effects of corticosteroids on reproduction in male rats and observed reversible adverse effects on accessory sex organs such as decreased weight and changes in the prostate and seminal vesicles of the animals without any changes in the sperm count, motility, or morphology. Burnell et al [50] compared family size in patients with $\mathrm{CD}$ who were administered steroids or sulfasalazine. They showed that family size decreased independent of medical therapy, and no significant difference was observed between men who did not receive steroids and those who received steroids for $<6$ and $>6$ months. Additionally, the administration of steroids concomitant with the immunomodulator azathioprine (AZA), did not adversely affect semen quality [51]. Therefore, no significant association was observed between corticosteroid use and male infertility. However, large-scale studies are needed to draw definitive conclusions in this regard.

\section{(3) Immunomodulators}

Immunomodulators are drugs that modify the activity of the immune system and also possess antiinflammatory properties. Patients may show symptom resolution several months after using the medication. However, maintenance and combination therapy are used in patients with IBD [47]. AZA and 6-mercaptopurine (6-MP) are the main immunomodulators used in patients with IBD, in addition to methotrexate (MTX), cyclosporine, and tacrolimus [47,51].

\section{(1) Thiopurines}

Thiopurines such as AZA and 6-MP are useful to maintain remission in steroid-dependent or refractory cases of IBD for their steroid-sparing effect [52,53]. AZA is a prodrug and non-enzymatically metabolized to 6-MP; however, 6-MP is metabolized by thiopurine S-methyl transferase to 6-thioguanine nucleotides and 6-methylmercaptopurine (Fig. 1) [54,55].

A few studies using animal models have shown AZA-induced teratogenicity causing malformations of the extremities and genetic injury to sperm $[55,56]$. In another study [57], the incidence of pregnancy-related complications was higher in women who became pregnant within 3 months of using 6-MP than in women in whom the drug was discontinued or not used at all [57]. However, several other studies report a negative association between thiopurine and infertility in patients with IBD [51,58,59]. Dejaco et al [51] reported the influence of AZA therapy on semen quality in men with IBD as follows: 18 men showed no difference in sperm density, motility, morphology, ejaculate volume, or the total sperm count evaluated by semen analyses before and after AZA treatment. However, when concomitant therapy with sulfasalazine was used, semen quality was diminished. Francella et al [58] reported a retrospective cohort study comprising 155 patients with IBD (79 women and 76 men) and showed that 6-MP did not produce adverse pregnancy outcomes, such as major congenital abnormalities, spontaneous abortions, anembryonic pregnancy, and embryonic demise. Teruel et al [59] showed no significant difference in unsuccessful pregnancies among couples in whom the men received mercaptopurine and AZA when compared with the control group. A meta-analysis showed that thiopurine use in women with IBD was associated with preterm birth, despite no association with low birth weight and/

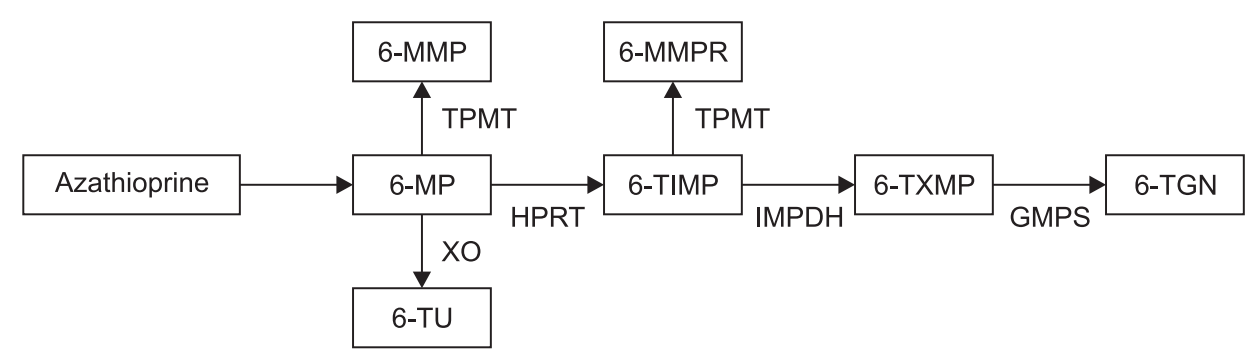

Fig. 1. Figure showing thiopurine metabolism. 6-MMP: 6-methylmercaptopurine, 6-MP: 6-mercaptopurine, 6-TU: 6-thiouric acid, TPMT: thiopurine S-methyltransferase, XO: xanthine oxidase, HPRT: hypoxanthine phosphoribosytransferase, 6-MMPR: 6-methylmercaptopurine riboside, 6-TIMP: 6-thioinosine 5'-monophosphate, IMPDH: inosine 5'-monophosphate dehydrogenase, 6-TXMP: 6-thioxanthylic acid, GMPS: guanosine 5'-monophosphate synthetase, 6-TGN: 6-thioguanine nucleotides. 
or congenital abnormalities. In men with IBD, thiopurine use was not associated with the risk of congenital abnormalities (pooled odds ratio, 1.87; 95\% confidence interval, 0.67-5.25) [60]. Adverse pregnancy outcomes have been reported in animal studies and in a few human studies; however, overall it does not appear to significantly affect male sexual function. However, men with IBD whose partners are planning to become pregnant need to be fully aware of the potential adverse effects of this therapy to choose the optimal medication.

\section{(2) Methotrexate}

MTX is a dihydrofolate reductase inhibitor, and its cytotoxic effect is unclear [47]. It is known to inhibit cytokine and eicosanoid synthesis and effectively treats several autoimmune diseases including IBD secondary to its anti-inflammatory action [47]. MTX is often used as a second-line immunomodulatory agent in patients with IBD who are resistant or intolerant to AZA or 6-MP [47]. It is contraindicated during pregnancy owing to its teratogenicity [61]. There is a lack of studies discussing the association between MTX and male SD; however, MTX is associated with oligospermia owing to its anti-folate actions with consequent inhibition of DNA synthesis and cell proliferation [38]. MTX potentially affects sexual functions through its cytotoxic, teratogenic, and mutagenic actions [62-64]. Cytotoxicity plays a role at the level of spermatogenesis or via direct injury to the sperm after crossing the blood-testis barrier causing oligospermia or dysfunctional sperm. Teratogenicity of MTX might be caused by transfer of chemicals to the female partner via seminal fluid during sexual intercourse. Mutagenicity of MTX is related to its role in altering genetic material that is at risk of inheriting the affected sperm $[62,65]$. In animal studies, MTX has been shown to cause significant disruption of the basement membrane, as well as produce cytotoxic effects on seminiferous tubule proliferation, and degeneration of spermatocytes and Sertoli and Leydig cells [66]. Grunnet et al [67] reported that the adverse effects of MTX manifested by abnormal semen analysis performed in 10 men with severe psoriasis using MTX were not significantly different from those in men using steroids. El-Beheiry et al [68] reported no significant abnormalities in terms of semen quality, testicular histopathological features, and spermatogenic activity in 26 men with psoriasis receiving MTX. Recently, Ley et al [69] published a case-control study that investigated the effects of MTX on sperm quality and genetic integrity. Notably, 7 men with IBD who received MTX for $>3$ months showed significantly decreased sperm integrity and DNA fragmentation and damage secondary to oxidative stress compared with age-matched men in a study performed across different fertility centers.

However, although MTX therapy affects sperm integrity, to date, the pregnancy-related adverse effects of MTX-exposed male's offspring are unclear [10]. Sussman and Leonard [70] reported severe oligospermia in men receiving MTX for severe psoriasis; however, normal sperm concentrations were observed after discontinuation of MTX. Therefore, the authors recommended that men whose partners are planning to conceive should discontinue MTX therapy 36 months prior to planning the pregnancy [61].

\section{(3) Cyclosporine and tacrolimus}

Cyclosporine A (CsA) and tacrolimus are classified as category $\mathrm{C}$ medications for use during pregnancy by the Food and Drug Administration [61]. CsA is a calcineurin inhibitor, which causes immunosuppression of $\mathrm{T}$ cells through blockage of $I L-2$ gene transcription [47]. In animal models, CsA use in male rats has been shown to cause abnormal sperm, oligospermia, abnormal sperm motility, decreased testis weight and serum testosterone concentration [38,71]. In another study, high-dose (10 mg/kg/d) CsA usage was associated with decreased sperm motility and serum testosterone levels [38,72]. However, the dose used in the study was relatively high compared with doses commonly used in patients with IBD. A meta-analysis of 15 studies reported that CsA did not cause significant adverse events, such as prematurity, major malformations, and low birth weight [73]. A few case studies have reported the safety of CsA use at 27 weeks in women with fulminant UC. No study has discussed infertility in men with IBD using CsA.

Tacrolimus is also a calcineurin inhibitor that is often used in steroid-refractory thiopurine naïve patients with UC [74]. Tacrolimus use is associated with a 5.6\% rate of malformations [61] and a high incidence of perinatal hyperkalemia and prematurity [75,76]. A case study of pregnancy and neonatal outcomes associated with tacrolimus use in patients showing refractory UC reported successful pregnancy outcomes and childbirth [77]. 


\section{(4) Anti-tumor necrosis factor agents}

Tumor necrosis factor- $\alpha(\mathrm{TNF}-\alpha)$ is a pro-inflammatory cytokine with a significant role in chronic inflammatory diseases such as IBD, rheumatoid arthritis, and psoriasis [78]. Anti-TNF agents such as infliximab (IFX) and adalimumab (ADA) are important treatment options for patients with moderate-to-severe active IBD as induction and maintenance therapy [38,47]. IFX is a chimeric monoclonal immunoglobulin (Ig) G1 antibody against TNF, and ADA is a human anti-TNF monoclonal antibody that is administered as a subcutaneous injection [78]. A few studies have investigated the effects of IFX in men with IBD. A few other studies have investigated the association between anti-TNF agents and male fertility. In one study of 146 patients who were exposed to IFX before and after pregnancy, 131 women were exposed directly and 15 women were indirectly exposed through partners, of which only 10 of 15 exposed by men were available outcome data. And they did not show adverse outcomes [79]. Mahadevan et al [72] reported that IFX therapy in 10 men with IBD showed a significant increase in semen volume until a week after infusion; however, men who received IFX as maintenance therapy showed a lower rate of normal oval forms of sperm after infusion. Moreover, the study suggested a possible mechanism to explain the TNF-re- lated changes in sperm motility and morphology. Spermiogenesis occurs in the testicular syncytium. The process of transformation of spermatids into spermatozoa involves "individualization" of sperm to remove nearly the entire cytoplasm. This process of cytoplasmic extrusion is mediated by Drosophila by TNF- $\alpha$ dependent caspase family proteases [80]. Anti-TNF- $\alpha$ can block TNF activity and reduce the caspase activity with consequent extrusion of the cytoplasm from the sperm during the natural process of development. This may be related to abnormal sperm motility and morphology [72]. Puchner et al [81] reported a systematic review of 60 cases in which expectant fathers used anti-TNF agents before their partners conceived and this did not cause adverse pregnancy outcomes and male infertility. Data regarding the association between anti-TNF and male infertility are limited, and further research is needed.

\section{(5) Other biological agents}

Recently, various biological agents such as antiintegrin agents (natalizumab, vedolizumab) and anti-IL 12-23 (ustekinumab) have been used in patients with IBD in addition to the use of anti-TNF agents. AntiTNF agents that are not as commonly used as IFX and ADA (certolizumab and golimumab) are also being ad-

Table 3. Association between medical therapy and pregnancy-related factors in men with inflammatory bowel disease

\begin{tabular}{|c|c|c|c|}
\hline & Sexual dysfunction \& infertility & Adverse events of pregnancy & Recommendation \\
\hline Sulfasalazine & $\begin{array}{l}\text { - Erectile dysfunction } \\
\text { - Oligospermia } \\
\text { - Poor sperm motility } \\
\text { - Increased forms of abnormal sperm } \\
\text { (reversible) [41-45] }\end{array}$ & $\begin{array}{l}\text { Possible (congenital } \\
\text { malformations) [10] }\end{array}$ & $\begin{array}{l}\text { Stop medication or switch to a different } \\
\text { class of 5-ASA medications }\end{array}$ \\
\hline Mesalamine & Oligospermia [46] & No & $\begin{array}{l}\text { Discontinue only in patients with stable } \\
\text { disease }\end{array}$ \\
\hline Corticosteroids & No & No & Recommended short-term use \\
\hline Thiopurines & No & Controversial $[51,58,59]$ & $\begin{array}{l}\text { Counsel regarding the possibility of } \\
\text { teratogenic effects on sperm }\end{array}$ \\
\hline MTX & $\begin{array}{l}\text { Erectile dysfunction } \\
\text { Altered spermatogenesis } \\
\text { Oligospermia } \\
\text { Teratogenicity [62-65] }\end{array}$ & No [10] & $\begin{array}{l}\text { Discontinue in patients with erectile } \\
\text { dysfunction }\end{array}$ \\
\hline Cyclosporine & $\begin{array}{l}\text { Decreased sperm motility and } \\
\text { testosterone (high dose) }[38,72]\end{array}$ & No [73] & No recommendations \\
\hline Infliximab & $\begin{array}{l}\text { Decreased sperm motility and } \\
\text { abnormal sperm morphology [72] }\end{array}$ & No [79] & No recommendations \\
\hline $\begin{array}{l}\text { Other biological } \\
\text { agents }\end{array}$ & No [83] & No $[10,81-84]$ & No recommendations \\
\hline
\end{tabular}

5-ASA: 5-aminosalicylic acid, MTX: methotrexate. 
ministered to patients with IBD [81]. Notably, few studies have discussed the association between newer biological agents and male reproductive function. Based on a few previous studies, the use of biological agents in pregnant women with IBD is associated with a low risk [81]. Natalizumab is a human IgG4 monoclonal antibody with immunomodulatory action via its role in blocking the $\alpha 4$ subunits of the $\alpha 4 \beta 1$ and $\alpha 4 \beta 7$ integrin molecules of the immune system [82]. Ebrahimi et al [82] reported pregnancy and fetal outcomes in 101 women with multiple sclerosis who received natalizumab and showed no adverse pregnancy outcomes. Vedolizumab is a gut-specific IgG1 monoclonal antibody to $\alpha 4 \beta 7$ integrin [83]. Mahadevan et al [83] assessed pregnancy outcomes in total 46 women, including 27 women who received vedolizumab and 19 women who were exposed by male partners. Of the 19 women (whose partners received vedolizumab), 11 had normal births, 2 were spontaneous abortions, 3 were elective terminations, and 3 had undocumented outcomes in the study. Although this study included a small sample size, there were no significant differences in pregnancy outcomes between healthy patients in the control group and vedolizumab users [83]. Ustekinumab is an IgG1 monoclonal antibody and acts as an inhibitor of $\Pi-12$ and $\mathrm{IL}$ 23 receptors [84]. Cortes et al [85] reported a case report of a woman with $\mathrm{CD}$ who received ustekinumab who conceived during treatment and delivered a healthy infant even with maintenance ustekinumab therapy. We summarized the association between medical therapy and pregnancy-related factors in men with IBD (Table $3)$.

\section{3) Disease activity}

Disease activity is an important parameter because the extent of disease activity of IBD determines the treatment regimen. Patients present with symptoms such as abdominal pain, diarrhea, and bleeding during the active disease phase of IBD [47]. A few studies have suggested that disease activity could affect the results of semen analysis and male sexual function [5,10]. Reportedly, the stage of active inflammation in patients with IBD tends to be associated with the release and action of inflammation-related pro-inflammatory cytokines such as TNF- $\alpha$ and IL-1, and oxidative stress, which may affect fertility [86]. Bel et al [5] showed that men with active IBD demonstrated a greater degree of SD than men undergoing remission or healthy con- trols. These men showed a lower rate of orgasms and overall sexual satisfaction than healthy controls and a higher rate of SD (greater ED and lower orgasmic ability, desire and sexual gratification) than men with IBD undergoing remission. Timmer et al [87] reported that men with IBD showing remission or mild disease did not show any difference in SD compared with healthy controls; however, men with IBD with severe active disease show a greater degree of SD such as erectile and orgasmic dysfunction and lower sexual desire and satisfaction than healthy controls. Therefore, controlling IBD is important in men whose partners are planning to conceive or actually conceive.

\section{4) Nutrition and lifestyle factors including smoking and alcohol intake}

Based on the European Society for Parenteral and Enteral Nutrition guidelines, it is known that malnutrition is highly prevalent in patients with IBD [88], and poor nutritional status in men with IBD might cause SD [89]. Zinc is an important factor involved in male fertility. Zinc plays an important role in optimal testicular function by affecting sperm motility, spermatogenesis, and maintaining optimal serum androgen levels [90]. El-Tawil [90] suggested that zinc deficiency may contribute to male infertility. Abbasi et al [91] reported oligospermia in 4 of 5 men with a restricted zinc intake over 24 to 40 weeks.

Alcohol and tobacco are known to cause well-known effects in patients with IBD. Alcohol use in patients with IBD is known to cause relapse or symptom aggravation from an inactive state [92]. Several studies have shown an association between alcohol consumption and fertility, including the effects of alcohol on testicular atrophy, decreased libido, and a decrease in the sperm count $[93,94]$.

Smoking is a known risk factor for CD, although it shows a protective effect in patients with UC [1]. The exact mechanism that explains this difference is unclear. Several studies have reported an association between smoking and sexual function in men and reported that smoking causes a reduction in the sperm count and density, and also affects sperm motility and morphology $[94,95]$. No studies have discussed the effects of smoking in patients with IBD. However, the deleterious effects of alcohol and tobacco are well-documented and the use of these substances should be discontinued. Therefore, the direct relevance of lifestyle including 
nutrition, alcohol and tobacco to infertility and SD in IBD patients is unclear and further research is needed.

\section{5) Psychological factors}

Quality of life and sexual functions are affected by symptoms such as diarrhea, fatigue, and abdominal pain in men with IBD. Additionally, depression is commonly reported to be associated with decreased quality of life [47,96]. Gollenberg et al [97] reported an association between stressful life events and semen parameters in that stressful life events led to diminished semen quality. The most common hypothesis in this regard is that stressful events may cause lowering of serum levels of testosterone and luteinizing hormone, which consequently interferes with spermatogenesis [98,99]. Timmer et al [87] reported a study in which 153 men with IBD were compared with matched pairs and showed similar sexual function; however, depression led to SD, which manifested as ED, low sexual desire, and low levels of overall satisfaction. Additionally, Bel et al [5] suggested that depression is the most important factor associated with SD in patients with IBD. Therefore, optimal management of the quality of life and psychological factors is important in patients with IBD. Further studies are required to investigate these and related issues.

\section{CONCLUSIONS}

Epidemiological data show that IBD predominantly affects relatively young patients of reproductive age. Therefore, adequate knowledge of the several factors causing IBD-induced SD is important. This study reviewed the association between male sexual function and surgery, medication, lifestyle habits such as alcohol and tobacco use, nutritional status, and psychological factors in men with IBD. Although no large-scale studies have been performed in this context, most studies suggest that 5-ASA and MTX should be discontinued before conception, if possible. The role of rectal surgery and medications including AZA, steroids, and biological agents is controversial, although no study has reported significant adverse effects on pregnancy outcomes associated with their use. Therefore, treatment needs to be individualized through discussion with physicians considering the disease activity and specific clinical situations. Additionally, this review revealed that discontinuing alcohol and tobacco use, improving nutritional status, and improving mental health help to control the disease and improve patients' quality of life.

\section{Disclosure}

The authors have no potential conflicts of interest to disclose.

\section{Author Contribution}

Conceptualization: YEP. Data curation: YEP. Formal analysis: YEP. Investigation: YEP. Methodology: YEP. Validation: TOK. Visualization: YEP. Writing-original draft: YEP. Writing-review \& editing: TOK.

\section{REFERENCES}

1. Ponder A, Long MD. A clinical review of recent findings in the epidemiology of inflammatory bowel disease. Clin Epidemiol 2013;5:237-47.

2. O'Toole A, Winter D, Friedman S. Review article: the psychosexual impact of inflammatory bowel disease in male patients. Aliment Pharmacol Ther 2014;39:1085-94.

3. Yang SK, Yun S, Kim JH, Park JY, Kim HY, Kim YH, et al. Epidemiology of inflammatory bowel disease in the SongpaKangdong district, Seoul, Korea, 1986-2005: a KASID study. Inflamm Bowel Dis 2008;14:542-9.

4. Kim BJ, Song SM, Kim KM, Lee YJ, Rhee KW, Jang JY, et al. Characteristics and trends in the incidence of inflammatory bowel disease in Korean children: a single-center experience. Dig Dis Sci 2010;55:1989-95.

5. Bel LG, Vollebregt AM, Van der Meulen-de Jong AE, Fidder HH, Ten Hove WR, Vliet-Vlieland CW, et al. Sexual dysfunctions in men and women with inflammatory bowel disease: the influence of IBD-related clinical factors and depression on sexual function. J Sex Med 2015;12:1557-67.

6. Mahmood S, Nusrat S, Crosby A, Zhao YD, Ali T. Assessment of sexual function among inflammatory bowel disease patients. Am J Gastroenterol 2015;110:601-3.

7. Buvat J, Glasser D, Neves RC, Duarte FG, Gingell C, Moreira ED Jr. Sexual problems and associated help-seeking behavior patterns: results of a population-based survey in France. Int J Urol 2009;16:632-8.

8. Witting K, Santtila P, Varjonen M, Jern P, Johansson A, von der Pahlen B, et al. Female sexual dysfunction, sexual distress, and compatibility with partner. J Sex Med 2008;5:258799.

9. Allocca M, Gilardi D, Fiorino G, Furfaro F, Peyrin-Biroulet L, Danese S. Sexual and reproductive issues and inflammatory 
bowel disease: a neglected topic in men. Eur J Gastroenterol Hepatol 2018;30:316-22.

10. Feagins LA, Kane SV. Sexual and reproductive issues for men with inflammatory bowel disease. Am J Gastroenterol 2009; 104:768-73.

11. Guyatt G, Mitchell A, Irvine EJ, Singer J, Williams N, Goodacre $\mathrm{R}$, et al. A new measure of health status for clinical trials in inflammatory bowel disease. Gastroenterology 1989;96: 804-10.

12. Rosen RC, Riley A, Wagner G, Osterloh IH, Kirkpatrick J, Mishra A. The international index of erectile function (IIEF): a multidimensional scale for assessment of erectile dysfunction. Urology 1997;49:822-30.

13. Weinfurt KP, Lin L, Bruner DW, Cyranowski JM, Dombeck $\mathrm{CB}$, Hahn EA, et al. Development and initial validation of the PROMIS $\left(^{\circ}\right)$ sexual function and satisfaction measures version 2.0. J Sex Med 2015;12:1961-74.

14. Eluri S, Cross RK, Martin C, Weinfurt KP, Flynn KE, Long $\mathrm{MD}$, et al. Inflammatory bowel diseases can adversely impact domains of sexual function such as satisfaction with sex life. Dig Dis Sci 2018;63:1572-82.

15. Sprangers MA, te Velde A, Aaronson NK. The construction and testing of the EORTC colorectal cancer-specific quality of life questionnaire module (QLQ-CR38). European Organization for Research and Treatment of Cancer Study Group on Quality of Life. Eur J Cancer 1999;35:238-47.

16. Timmer A, Bauer A, Kemptner D, Fürst A, Rogler G. Determinants of male sexual function in inflammatory bowel disease: a survey-based cross-sectional analysis in 280 men. Inflamm Bowel Dis 2007;13:1236-43.

17. O’Toole A, de Silva PS, Marc LG, Ulysse CA, Testa MA, Ting A, et al. Sexual dysfunction in men with inflammatory bowel disease: a new IBD-specific scale. Inflamm Bowel Dis 2018; 24:310-6

18. Friedman S, Magnussen B, O’Toole A, Fedder J, Larsen MD, Nørgård BM. Increased use of medications for erectile dysfunction in men with ulcerative colitis and crohn's disease compared to men without inflammatory bowel disease: a nationwide cohort study. Am J Gastroenterol 2018;113:135562.

19. Lindsay TJ, Vitrikas KR. Evaluation and treatment of infertility. Am Fam Physician 2015;91:308-14.

20. Sahin A, Urkmez A, Verit A, Yuksel OH, Verit FF. Psychologic and sexual dysfunction in primary and secondary infertile male patients. Arch Ital Urol Androl 2017;89:120-4.

21. Hwang JM, Varma MG. Surgery for inflammatory bowel disease. World J Gastroenterol 2008;14:2678-90.

22. Latella G, Vernia P, Viscido A, Frieri G, Cadau G, Cocco A, et al. GI distension in severe ulcerative colitis. Am J Gastroenterol 2002;97:1169-75.

23. Seifarth C, Kreis ME, Gröne J. Indications and specific surgical techniques in Crohn's disease. Viszeralmedizin 2015;31: 273-9.

24. Galandiuk S, Kimberling J, Al-Mishlab TG, Stromberg AJ. Perianal Crohn disease: predictors of need for permanent diversion. Ann Surg 2005;241:796-801; discussion 801-2.

25. Mueller MH, Geis M, Glatzle J, Kasparek M, Meile T, Jehle EC, et al. Risk of fecal diversion in complicated perianal Crohn's disease. J Gastrointest Surg 2007;11:529-37.

26. Cohen JL, Strong SA, Hyman NH, Buie WD, Dunn GD, Ko $\mathrm{CY}$, et al. Practice parameters for the surgical treatment of ulcerative colitis. Dis Colon Rectum 2005;48:1997-2009.

27. Metcalf AM. Elective and emergent operative management of ulcerative colitis. Surg Clin North Am 2007;87:633-41.

28. Slors FJ, van Zuijlen PP, van Dijk GJ. Sexual and bladder dysfunction after total mesorectal excision for benign diseases. Scand J Gastroenterol Suppl 2000;(232):48-51.

29. Farouk R, Pemberton JH, Wolff BG, Dozois RR, Browning S, Larson D. Functional outcomes after ileal pouch-anal anastomosis for chronic ulcerative colitis. Ann Surg 2000;231:91926.

30. Berndtsson I, Oresland T, Hultén L. Sexuality in patients with ulcerative colitis before and after restorative proctocolectomy: a prospective study. Scand J Gastroenterol 2004; 39:374-9.

31. Hueting WE, Buskens E, van der Tweel I, Gooszen HG, van Laarhoven CJ. Results and complications after ileal pouch anal anastomosis: a meta-analysis of 43 observational studies comprising 9,317 patients. Dig Surg 2005;22:69-79.

32. Lindsey I, George BD, Kettlewell MG, Mortensen NJ. Impotence after mesorectal and close rectal dissection for inflammatory bowel disease. Dis Colon Rectum 2001;44:831-5.

33. van Balkom KA, Beld MP, Visschers RG, van Gemert WG, Breukink SO. Long-term results after restorative proctocolectomy with ileal pouch-anal anastomosis at a young age. Dis Colon Rectum 2012;55:939-47.

34. Gorgun E, Remzi FH, Montague DK, Connor JT, O’Brien $\mathrm{K}$, Loparo B, et al. Male sexual function improves after ileal pouch anal anastomosis. Colorectal Dis 2005;7:545-50.

35. Lindsey I, George B, Kettlewell M, Mortensen N. Randomized, double-blind, placebo-controlled trial of sildenafil (Viagra) for erectile dysfunction after rectal excision for cancer and inflammatory bowel disease. Dis Colon Rectum 2002;45: 727-32.

36. Kuruvilla K, Osler T, Hyman NH. A comparison of the quality of life of ulcerative colitis patients after IPAA vs ileos- 
tomy. Dis Colon Rectum 2012;55:1131-7.

37. Lim WC, Wang Y, MacDonald JK, Hanauer S. Aminosalicylates for induction of remission or response in Crohn's disease. Cochrane Database Syst Rev 2016;7:CD008870.

38. Sands K, Jansen R, Zaslau S, Greenwald D. Review article: the safety of therapeutic drugs in male inflammatory bowel disease patients wishing to conceive. Aliment Pharmacol Ther 2015;41:821-34.

39. Toovey S, Hudson E, Hendry WF, Levi AJ. Sulphasalazine and male infertility: reversibility and possible mechanism. Gut 1981;22:445-51.

40. Alonso V, Linares V, Bellés M, Albina ML, Sirvent JJ, Domingo JL, et al. Sulfasalazine induced oxidative stress: a possible mechanism of male infertility. Reprod Toxicol 2009;27:3540.

41. O’Moráin C, Smethurst P, Doré CJ, Levi AJ. Reversible male infertility due to sulphasalazine: studies in man and rat. Gut 1984;25:1078-84.

42. Di Paolo MC, Paoluzi OA, Pica R, Iacopini F, Crispino P, Rivera $M$, et al. Sulphasalazine and 5-aminosalicylic acid in long-term treatment of ulcerative colitis: report on tolerance and side-effects. Dig Liver Dis 2001;33:563-9.

43. Zelissen PM, van Hattum J, Poen H, Scholten P, Gerritse R, te Velde ER. Influence of salazosulphapyridine and 5-aminosalicylic acid on seminal qualities and male sex hormones. Scand J Gastroenterol 1988;23:1100-4.

44. Chatzinoff M, Guarino JM, Corson SL, Batzer FR, Friedman LS. Sulfasalazine-induced abnormal sperm penetration assay reversed on changing to 5-aminosalicylic acid enemas. Dig Dis Sci 1988;33:108-10.

45. Riley SA, Lecarpentier J, Mani V, Goodman MJ, Mandal BK, Turnberg LA. Sulphasalazine induced seminal abnormalities in ulcerative colitis: results of mesalazine substitution. Gut 1987;28:1008-12.

46. Chermesh I, Eliakim R. Mesalazine-induced reversible infertility in a young male. Dig Liver Dis 2004;36:551-2.

47. Mowat C, Cole A, Windsor A, Ahmad T, Arnott I, Driscoll R, et al. Guidelines for the management of inflammatory bowel disease in adults. Gut 2011;60:571-607.

48. Saruta M. Steroid therapy for inflammatory bowel disease. Nihon Rinsho 2017;75:398-402.

49. Lerman SA, Miller GK, Bohlman K, Albaladejo V, Léonard JF, Devas V, et al. Effects of corticosterone on reproduction in male Sprague-Dawley rats. Reprod Toxicol 1997;11:799805.

50. Burnell D, Mayberry J, Calcraft BJ, Morris JS, Rhodes J. Male fertility in Crohn's disease. Postgrad Med J 1986;62:269-72.

51. Dejaco C, Mittermaier C, Reinisch W, Gasche C, Waldhoer T,
Strohmer H, et al. Azathioprine treatment and male fertility in inflammatory bowel disease. Gastroenterology 2001;121: 1048-53.

52. Present DH, Korelitz BI, Wisch N, Glass JL, Sachar DB, Pasternack BS. Treatment of Crohn's disease with 6-mercaptopurine. A long-term, randomized, double-blind study. N Engl J Med 1980;302:981-7.

53. Timmer A, McDonald JW, Tsoulis DJ, Macdonald JK. Azathioprine and 6-mercaptopurine for maintenance of remission in ulcerative colitis. Cochrane Database Syst Rev 2012; (9):CD000478.

54. Lee KM, Kim YS, Seo GS, Kim TO, Yang SK. Use of thiopurines in inflammatory bowel disease: a consensus statement by the Korean Association for the Study of Intestinal Diseases (KASID). Intest Res 2015;13:193-207.

55. Zelinkova Z, Derijks LJ, Stokkers PC, Vogels EW, van Kampen AH, Curvers WL, et al. Inosine triphosphate pyrophosphatase and thiopurine s-methyltransferase genotypes relationship to azathioprine-induced myelosuppression. Clin Gastroenterol Hepatol 2006;4:44-9.

56. Ligumsky M, Badaan S, Lewis H, Meirow D. Effects of 6-mercaptopurine treatment on sperm production and reproductive performance: a study in male mice. Scand J Gastroenterol 2005;40:444-9.

57. Rajapakse RO, Korelitz BI, Zlatanic J, Baiocco PJ, Gleim GW. Outcome of pregnancies when fathers are treated with 6-mercaptopurine for inflammatory bowel disease. Am J Gastroenterol 2000;95:684-8.

58. Francella A, Dyan A, Bodian C, Rubin P, Chapman M, Present DH. The safety of 6-mercaptopurine for childbearing patients with inflammatory bowel disease: a retrospective cohort study. Gastroenterology 2003;124:9-17.

59. Teruel C, López-San Román A, Bermejo F, Taxonera C, Pérez-Calle JL, Gisbert JP, et al. Outcomes of pregnancies fathered by inflammatory bowel disease patients exposed to thiopurines. Am J Gastroenterol 2010;105:2003-8.

60. Akbari M, Shah S, Velayos FS, Mahadevan U, Cheifetz AS. Systematic review and meta-analysis on the effects of thiopurines on birth outcomes from female and male patients with inflammatory bowel disease. Inflamm Bowel Dis 2013;19:1522.

61. Mahadevan U. Fertility and pregnancy in the patient with inflammatory bowel disease. Gut 2006;55:1198-206.

62. Gutierrez JC, Hwang K. The toxicity of methotrexate in male fertility and paternal teratogenicity. Expert Opin Drug Metab Toxicol 2017;13:51-8

63. Sukhotnik I, Nativ O, Roitburt A, Bejar D, Coran AG, Mogilner JG, et al. Methotrexate induces germ cell apoptosis and 
impairs spermatogenesis in a rat. Pediatr Surg Int 2013;29: 179-84.

64. Klemmt L, Scialli AR. The transport of chemicals in semen. Birth Defects Res B Dev Reprod Toxicol 2005;74:119-31.

65. Johnsen SG. Testicular biopsy score count-a method for registration of spermatogenesis in human testes: normal values and results in 335 hypogonadal males. Hormones 1970;1: 2-25.

66. Saxena AK, Dhungel S, Bhattacharya S, Jha CB, Srivastava AK. Effect of chronic low dose of methotrexate on cellular proliferation during spermatogenesis in rats. Arch Androl 2004;50:33-5.

67. Grunnet E, Nyfors A, Hansen KB. Studies of human semen in topical corticosteroid-treated and in methotrexate-treated psoriatics. Dermatologica 1977;154:78-84.

68. El-Beheiry A, El-Mansy E, Kamel N, Salama N. Methotrexate and fertility in men. Arch Androl 1979;3:177-9.

69. Ley D, Jones J, Parrish J, Salih S, Caldera F, Tirado E, et al. Methotrexate reduces DNA integrity in sperm from men with inflammatory bowel disease. Gastroenterology 2018; 154:2064-7.e3.

70. Sussman A, Leonard JM. Psoriasis, methotrexate, and oligospermia. Arch Dermatol 1980;116:215-7.

71. Serghini M, Fekih M, Karoui S, Ben Mustapha N, Kallel L, Matri S, et al. [Fertility and inflammatory bowel diseases]. Tunis Med 2010;88:623-8. French.

72. Mahadevan U, Terdiman JP, Aron J, Jacobsohn S, Turek P. Infliximab and semen quality in men with inflammatory bowel disease. Inflamm Bowel Dis 2005;11:395-9.

73. Bar Oz B, Hackman R, Einarson T, Koren G. Pregnancy outcome after cyclosporine therapy during pregnancy: a metaanalysis. Transplantation 2001;71:1051-5.

74. Ogata H, Matsui T, Nakamura M, Iida M, Takazoe M, Suzuki $\mathrm{Y}$, et al. A randomised dose finding study of oral tacrolimus (FK506) therapy in refractory ulcerative colitis. Gut 2006;55: 1255-62.

75. Jain A, Venkataramanan R, Fung JJ, Gartner JC, Lever J, Balan V, et al. Pregnancy after liver transplantation under tacrolimus. Transplantation 1997;64:559-65.

76. Kainz A, Harabacz I, Cowlrick IS, Gadgil S, Hagiwara D. Analysis of 100 pregnancy outcomes in women treated systemically with tacrolimus. Transpl Int 2000;13 Suppl 1:S299300.

77. Baumgart DC, Sturm A, Wiedenmann B, Dignass AU. Uneventful pregnancy and neonatal outcome with tacrolimus in refractory ulcerative colitis. Gut 2005;54:1822-3.

78. Rutgeerts P, Van Assche G, Vermeire S. Optimizing antiTNF treatment in inflammatory bowel disease. Gastroenter- ology 2004;126:1593-610.

79. Katz JA, Antoni C, Keenan GF, Smith DE, Jacobs SJ, Lichtenstein GR. Outcome of pregnancy in women receiving infliximab for the treatment of Crohn's disease and rheumatoid arthritis. Am J Gastroenterol 2004;99:2385-92.

80. Huh JR, Vernooy SY, Yu H, Yan N, Shi Y, Guo M, et al. Multiple apoptotic caspase cascades are required in nonapoptotic roles for Drosophila spermatid individualization. PLoS Biol 2004;2:E15.

81. Puchner R, Danninger K, Puchner A, Pieringer H. Impact of TNF-blocking agents on male sperm characteristics and pregnancy outcomes in fathers exposed to TNF-blocking agents at time of conception. Clin Exp Rheumatol 2012;30: 765-7.

82. Ebrahimi N, Herbstritt S, Gold R, Amezcua L, Koren G, Hellwig K. Pregnancy and fetal outcomes following natalizumab exposure in pregnancy. A prospective, controlled observational study. Mult Scler 2015;21:198-205.

83. Mahadevan U, Vermeire S, Lasch K, Abhyankar B, Bhayat F, Blake A, et al. Vedolizumab exposure in pregnancy: outcomes from clinical studies in inflammatory bowel disease. Aliment Pharmacol Ther 2017;45:941-50.

84. Weitz JE, Ritchlin CT. Ustekinumab: targeting the IL-17 pathway to improve outcomes in psoriatic arthritis. Expert Opin Biol Ther 2014;14:515-26.

85. Cortes X, Borrás-Blasco J, Antequera B, Fernandez-Martinez S, Casterá E, Martin S, et al. Ustekinumab therapy for Crohn's disease during pregnancy: a case report and review of the literature. J Clin Pharm Ther 2017;42:234-6.

86. Sarkar O, Bahrainwala J, Chandrasekaran S, Kothari S, Mathur PP, Agarwal A. Impact of inflammation on male fertility. Front Biosci (Elite Ed) 2011;3:89-95.

87. Timmer A, Bauer A, Dignass A, Rogler G. Sexual function in persons with inflammatory bowel disease: a survey with matched controls. Clin Gastroenterol Hepatol 2007;5:87-94.

88. Forbes A, Escher J, Hébuterne X, Kłęk S, Krznaric Z, Schneider S, et al. ESPEN guideline: clinical nutrition in inflammatory bowel disease. Clin Nutr 2017;36:321-47.

89. Shin T, Okada H. Infertility in men with inflammatory bowel disease. World J Gastrointest Pharmacol Ther 2016;7:361-9.

90. El-Tawil AM. Zinc deficiency in men with Crohn's disease may contribute to poor sperm function and male infertility. Andrologia 2003;35:337-41.

91. Abbasi AA, Prasad AS, Rabbani P, DuMouchelle E. Experimental zinc deficiency in man. Effect on testicular function. J Lab Clin Med 1980;96:544-50.

92. Jussila A, Virta LJ, Pukkala E, Färkkilä MA. Mortality and causes of death in patients with inflammatory bowel disease: 
a nationwide register study in Finland. J Crohns Colitis 2014; 8:1088-96.

93. Sharma R, Biedenharn KR, Fedor JM, Agarwal A. Lifestyle factors and reproductive health: taking control of your fertility. Reprod Biol Endocrinol 2013;11:66.

94. Li Y, Lin H, Li Y, Cao J. Association between socio-psychobehavioral factors and male semen quality: systematic review and meta-analyses. Fertil Steril 2011;95:116-23.

95. Calogero A, Polosa R, Perdichizzi A, Guarino F, La Vignera S, Scarfia A, et al. Cigarette smoke extract immobilizes human spermatozoa and induces sperm apoptosis. Reprod Biomed Online 2009;19:564-71.
96. Graff LA, Walker JR, Bernstein CN. Depression and anxiety in inflammatory bowel disease: a review of comorbidity and management. Inflamm Bowel Dis 2009;15:1105-18.

97. Gollenberg AL, Liu F, Brazil C, Drobnis EZ, Guzick D, Overstreet JW, et al. Semen quality in fertile men in relation to psychosocial stress. Fertil Steril 2010;93:1104-11.

98. King JA, Rosal MC, Ma Y, Reed GW. Association of stress, hostility and plasma testosterone levels. Neuro Endocrinol Lett 2005;26:355-60.

99. Klimek M, Pabian W, Tomaszewska B, Kołodziejczyk J. Levels of plasma ACTH in men from infertile couples. Neuro Endocrinol Lett 2005;26:347-50. 